\title{
DESIDRATAÇÃO OSMÓTICA DE MORANGOS CV. AROMAS
}

\author{
C. DE CAMPO ${ }^{1}$, S. H. FLÔRES ${ }^{1}$, L.R. ANTONIOLLI ${ }^{3}$ e \\ C. D. TELES ${ }^{2}$ \\ 1 - Universidade Federal do Rio Grande do Sul, Instituto de Ciência e Tecnologia de \\ Alimentos \\ 2 - Instituto Federal de Ciência e Tecnologia de Alimentos - IFRS - Campus Bento \\ Gonçalves. \\ 3 - Embrapa Uva e Vinho - Bento Gonçalves \\ E-mail para contato: simone.flores@ufrgs.br
}

\begin{abstract}
RESUMO - O morango possui conservação limitada após a colheita, por possuir elevada atividade de água, sendo suscetível às podridões causadas principalmente por Botrytis cinerea. A desidratação osmótica tem sido sugerida como uma operação unitária importante, em conjunto com secagem convectiva, na transformação de frutos perecíveis em novos produtos com maior vida de prateleira e maior valor agregado. O trabalho teve como objetivo avaliar a influência de três concentrações de solução osmótica (40, 60 e $80 \%$ ), bem como a influência do tempo de imersão de morangos cv. Aromas nas respectivas soluções osmóticas por 60, 120 e 180 minutos em banho-maria, com posterior secagem em estufa à vácuo por $24 \mathrm{~h} \mathrm{a} 65^{\circ} \mathrm{C}$. O aumento da concentração da solução osmótica proporcionou maior perda de massa, sendo que esta foi maior também para o tempo inicial de imersão em banho-maria de 60 minutos. $O$ tratamento utilizando concentração $80 \%$ de sacarose, no tempo de 60 minutos, proporcionou maior perda de água, e consequentemente, maior perda de massa, sendo, portanto, o tratamento mais favorável para o processo.
\end{abstract}

\section{INTRODUÇÃ̃O}

O Brasil é o terceiro maior produtor mundial de frutas frescas, com uma colheita anual de quase 40.000.000 toneladas (Sebrae, 2005). O morango (Fragaria x ananassa Duch) é produzido e apreciado nas mais variadas regiões do mundo por seu aspecto nutritivo e atrativo, pois é fonte de vitamina $\mathrm{C}$, potássio, cálcio e magnésio, dentre outros nutrientes, bem como por seu flavor agradável, sendo a espécie de maior expressão econômica entre as pequenas frutas (Oliveira et al., 2005; Campos; Rodovalho, 2009). Em 2006, o Brasil produziu cerca de 100 mil toneladas, cultivadas numa área próxima a 3.500 ha (Antunes, 2002). Esta produção é quase integralmente voltada para o mercado interno, sendo $30 \%$ destinada ao processamento e aproximadamente $70 \%$ destinada ao consumo in natura (Madail et al., 2007). 
A comercialização dos frutos in natura tem como limitante a rápida perda de qualidade pós-colheita (Del-Valle, 2005; Cia et al., 2007), sendo a vida útil do morango fresco de aproximadamente 5 dias quando mantido a baixas temperaturas $\left(0\right.$ a $\left.4^{\circ} \mathrm{C}\right)$ (Han et al., 2005; Vargas et al., 2006). A infecção fúngica exerce papel determinante na vida útil dos pequenos frutos, sendo o Botrytis cinerea responsável pela podridão cinzenta, a espécie mais encontrada (Haffner et al., 2002). Além da grande suscetibilidade à degradação fúngica, (Han et al., 2005; Vargas et al., 2006; Haffner et al., 2002) são considerados fatores limitantes à vida útil do morango sua fragilidade e alta taxa respiratória (Gonçalves et al., 2004; Han et al., 2005). A desidratação osmótica representa uma alternativa tecnológica para reduzir perdas póscolheita de frutos. Essa tecnologia tem sido usada, principalmente como pré-tratamento de alguns processos convencionais como a liofilização, a secagem à vácuo e a secagem por ar, a fim de melhorar a qualidade final, reduzir custos energéticos ou mesmo para desenvolver novos produtos. Na literatura existem trabalhos que exploram esse aspecto de utilização da desidratação como uma etapa prévia destes processos (Fernandes et al., 2006; Andrade et al., 2007).

Considerando as limitações tecnológicas para a obtenção de morangos desidratados com qualidade, a desidratação osmótica surge como uma opção à padronização deste processo, para obtenção de um produto com cor, textura e sabor adequados, além de possibilitar redução nas perdas pós-colheita do fruto, que apresenta barreiras em sua comercialização in natura devido à alta perecebilidade.

O objetivo do presente trabalho foi avaliar os efeito das variáveis do processo (concentração da solução osmótica e tempo de imersão) sobre a perda de massa, pH e ganho de sólidos solúveis de morangos cv. Aromas desidratados osmoticamente.

\section{MATERIAL E MÉTODOS}

\subsection{Matéria-prima}

Morangos cv. Aromas, em estádio maduro, caracterizado por cor vermelho brilhante e textura firme, foram obtidos no município de Vacaria - RS e acondicionados até o momento dos experimentos em câmara refrigerada a $0{ }^{\circ} \mathrm{C}$, em bandejas plásticas, envoltos por filme de policloreto de vinila (PVC), para evitar desidratação. O agente osmótico utilizado foi sacarose comercial, marca União, adquirida no mercado local.

\subsection{Preparo das amostras}

Os frutos foram selecionados conforme o estádio maturação e ausência de danos, com prioridade para frutos sadios e não sobre maduros, e foram lavados e higienizados por imersão em dióxido de cloro Tecsa ${ }^{\circledR C l o r}(0,05$ g L-1/1 minuto), sendo, em seguida, retiradas as folhas dos frutos. Utilizou-se 10 morangos para cada concentração e tempo de imersão. Realizou-se pesagem individual dos frutos, sendo estes enumerados de 1 a 10.

Após a pesagem, os frutos foram submetidos ao processo de branqueamento para inativação de enzimas. Os morangos foram imersos em $2 \mathrm{~L}$ de água destilada, com adição de 
cloreto de cálcio 0,2 g L-1, sendo esse utilizado, para melhorar a textura. Os frutos permaneceram na solução por 2 minutos a $100^{\circ} \mathrm{C}$. $\mathrm{O}$ branqueamento foi realizado individualmente para cada tratamento, e os morangos já pesados, foram colocados separadamente em uma grade, a fim de manter sua identificação, visto que foi avaliada a perda de massa individual de cada fruto.

Posteriormente ao branqueamento, os frutos foram acondicionados em copos plásticos contendo $50 \mathrm{~mL}$ de solução osmótica. Em seguida, copos foram fechados com filme de poliestireno, com o objetivo de evitar a perda de água da solução por evaporação.

\subsection{Preparo da solução osmótica}

As soluções osmóticas foram elaboradas em diferentes concentrações de sacarose: 40 60 e $80 \%$. As mesmas foram preparadas com água destilada, com agitação manual, à temperatura de $65^{\circ} \mathrm{C}$ em banho-maria, até completa solubilização da sacarose. Foi adicionado metabissulfito de sódio $(0,02 \%)$ às soluções osmóticas, a fim de melhorar a conservação dos frutos. As mesmas foram submetidas a um aquecimento em banho-maria até $30{ }^{\circ} \mathrm{C}$, alguns instantes antes de seu uso, para que estes permanecessem na mesma temperatura durante o tratamento. As soluções foram preparadas em volume de $500 \mathrm{~mL}$ e acondicionadas à temperatura ambiente, em balões volumétricos, sendo preparadas no dia anterior ao seu uso.

A desidratação osmótica foi realizada em banho-maria, em três diferentes tempos (60, 120 e 180 minutos), a temperatura de $30^{\circ} \mathrm{C}$, com agitação manual dos copos plásticos, a cada 15 minutos.

\subsection{Processo de desidratação osmótica}

Foram realizados nove tratamentos, utilizando-se 10 morangos para cada um, ou seja 10 morangos para cada combinação tempo de imersão x concentração da solução osmótica (Tabela 1). Realizou-se um ensaio por dia, e após os determinados tempos em banho-maria, os morangos foram submetidos à secagem em estufa a vácuo por $24 \mathrm{~h}$ na temperatura de $65^{\circ} \mathrm{C}$.

Tabela 1: Tratamentos realizados (combinação tempo de imersão x concentração da solução osmótica) na desidratação de morangos cv. Aromas

\begin{tabular}{lcccc}
\hline Tempo de imersão & \multicolumn{3}{c}{ Concentração da solução osmótica (\%) } \\
\cline { 3 - 4 } em & banho-maria & 40 & 60 & 80 \\
\hline min $)$ & & & & \\
\hline 60 & & Tratamento 1 & Tratamento 2 & Tratamento 3 \\
120 & Tratamento 4 & Tratamento 5 & Tratamento 6 \\
180 & & Tratamento 7 & Tratamento 8 & Tratamento 9 \\
\hline
\end{tabular}

Decorrido os tempos estabelecidos, os frutos foram retirados da solução osmótica e imersos, individualmente, em água destilada, por 5 segundos, sendo, posteriormente, secos em papel absorvente para retirada do excesso de água, antes da pesagem. 
Durante a secagem a estufa foi aberta nos tempos de 4 e 20 horas para a troca de posição dos morangos, para assim melhorar a distribuição de umidade e otimizar o processo de secagem. Posteriormente a secagem, os morangos foram acondicionados em embalagens de polietileno tereftalato identificadas e armazenadas até o momento das análises.

\subsection{Análises físico-químicas}

Foi realizada uma determinação de perda de peso total, $\mathrm{pH}$ e sólidos solúveis para cada tratamento. $\mathrm{O} \mathrm{pH}$ e teor de sólidos solúveis totais ( $\left.{ }^{\circ} \mathrm{Brix}\right)$, foram avaliados segundo metodologia proposta pela A.O.A.C (1995).

\subsection{Análise estatística}

Todas as análises foram realizadas em triplicata e os resultados foram avaliados por análise de variância (ANOVA) e teste de Tukey ao nível de significância de $5 \%$, utilizando o software Statistica 12.0 (Statsoft Inc).

\section{RESULTADOS E DISCUSSÃO}

\section{$3.1 \mathrm{pH}$}

Observando a Tabela 2, nota-se que não houve diferença estatística significativa para os valores de pH para as combinações tempo de imersão x concentração da solução de sacarose, exceto para o tempo de 120 minutos combinado com a concentração de $80 \%$ de sacarose, que apresentou um valor ligeiramente menor.

Tabela 2: Influência do tempo de imersão x concentração da solução osmótica sobre o pH dos morangos desidratados osmoticamente

\begin{tabular}{lcccc}
\hline Tempo & de imersão & \multicolumn{3}{c}{ Concentração da solução osmótica (\% sacarose) } \\
\cline { 3 - 5 } $\begin{array}{l}\text { em } \\
\text { ban })\end{array}$ & banho-maria & 40 & 60 & 80 \\
\hline 60 & & & $3,46 \pm 0,11^{\mathrm{aA}}$ & $3,42 \pm 0,08^{\mathrm{aA}}$ \\
120 & $3,34 \pm 0,10^{\mathrm{aA}}$ & $3,32 \pm 0,11^{\mathrm{aA}}$ & $3,17 \pm 0,07^{\mathrm{bB}}$ \\
180 & $3,37 \pm 0,08^{\mathrm{aA}}$ & $3,44 \pm 0,09^{\mathrm{aA}}$ & $3,49 \pm 0,06^{\mathrm{aA}}$ \\
\hline
\end{tabular}

Letras minúsculas diferentes na mesma coluna indicam diferença estatística significativa $(\mathrm{p}<0,05)$. Letras maiúsculas diferentes na mesma linha indicam diferença estatística significativa $(p<0,05)$.

\subsection{Ganho de sólidos solúveis}

O teor de sólidos solúveis dos morangos desidratados osmoticamente foi influenciado pelo tempo de imersão em banho-maria e concentração da solução osmótica apenas para um tratamento. Houve diferença estatística significativa para o tempo de 120 minutos combinado com a solução de $80 \%$ de sacarose, que apresentou um valor menor comparado com os demais resultados. Os resultados foram diferentes de Andrade et al. (2007), que demonstraram, na desidratação osmótica de pedaços de jenipapo a 30, 50 e $70 \%$ de sacarose, 
que as concentrações mais altas de sacarose favorecem a perda de água, promovendo, simultaneamente, maior ganho de sólidos solúveis. Teles et al. (2006) na desidratação osmótica de melão, também encontraram um maior ganho de sólidos solúveis para concentrações mais altas de sacarose.

Apesar de as concentrações mais altas de sacarose favorecerem a maior perda de peso, ao mesmo tempo, provocam maior ganho de sólidos solúveis. Este comportamento pode ser explicado pelo aumento da perda de umidade das amostras, o que facilitaria a entrada de solutos na fruta (Telis, et al., 2004). Segundo Torregiani (1993), o ideal é promover a perda de água com o menor ganho de sólidos solúveis, visto que a impregnação de solutos no alimento pode alterar as propriedades sensoriais e nutricionais do produto.

\subsection{Influência da concentração da solução osmótica na perda de massa}

Para avaliar a influência da concentração da solução osmótica na perda de massa durante a desidratação, observou-se os resultados de perda de massa total. De acordo com os resultados obtidos (Tabela 3), a maior perda de massa foi obtida ao utilizar a concentração de $80 \%$ de sacarose. Quanto maior for a concentração da solução, maior será a perda de água durante o processo, devido ao aumento da pressão osmótica externa (Mizkahi et al., 2001).

Esse resultado está de acordo com Khoyi e Hesari (2006) que estudaram a cinética da desidratação osmótica de damascos em solução de sacarose a $50 \%, 60 \%$ e $70 \%$ e concluíram que a perda de água e o ganho de sólidos aumentam com o aumento da concentração da solução. Viberg et al. (1998), ao estudarem duas variedades de morango (Honeoye e Dania) pré-tratados osmoticamente, observaram que a perda de água aumentou com a elevação da concentração de açúcar de 20 até $85 \%$ de sacarose.

Tabela 3: Influência do tempo de imersão x concentração da solução osmótica sobre o teor de sólidos solúveis dos morangos desidratados osmoticamente

\begin{tabular}{lcccc}
\hline Tempo & $\begin{array}{c}\text { de imersão } \\
\text { em }\end{array}$ & \multicolumn{3}{c}{ Concentração da solução osmótica (\% sacarose) } \\
\cline { 3 - 5 }$(\mathrm{min})$ & banho-maria & 40 & 60 & 80 \\
\hline 60 & & & $8,23 \pm 0,43^{\mathrm{aA}}$ & $10,15 \pm 1,05^{\mathrm{aA}}$ \\
120 & $8,23 \pm 0,43^{\mathrm{aA}}$ & $8,83 \pm 2,02^{\mathrm{aA}}$ & $7,53 \pm 1,09^{\mathrm{bB}}$ \\
180 & $8,43 \pm 1,10^{\mathrm{aA}}$ & $9,98 \pm 1,47^{\mathrm{aA}}$ & $10,10 \pm 0,94^{\mathrm{aA}}$ \\
\hline
\end{tabular}

Letras minúsculas diferentes na mesma coluna indicam diferença estatística significativa $(p<0,05)$. Letras maiúsculas diferentes na mesma linha indicam diferença estatística significativa $(p<0,05)$.

\subsection{Influência do tempo em banho-maria na perda de massa}

A Tabela 4 mostra as perdas de massa dos morangos nos diferentes tempos de banhomaria. Considerando a perda de massa dos frutos nos diferentes tempos de imersão na solução osmótica mantida em banho-maria, observou-se que houve diferença significativa para o tempo de 60 minutos comparado aos demais, visto que para este tempo, a perda de massa dos morangos foi maior. $\mathrm{O}$ resultado de maior perda de massa para o menor tempo de imersão está de acordo com Kowalska e Lenart (2001), que na desidratação osmótica de maçã, abóbora e cenoura, mostraram que as maiores taxas de perda de água e de ganho de sólidos 
ocorrem durante os primeiros 30 minutos do processo. Park et al. (2002) relataram maior perda de água e ganho de sólidos em cubos de pêra D'Anjou até os $40 \mathrm{~min}$ de imersão em solução osmótica.

Tabela 4: Perda de massa total dos morangos cv.Aromas desidratados osmoticamente

\begin{tabular}{lcccc}
\hline Tempo & $\begin{array}{c}\text { de imersão } \\
\text { em }\end{array}$ & \multicolumn{3}{c}{ Concentração da solução osmótica (\% sacarose) } \\
\cline { 3 - 5 }$($ min $)$ & banho-maria & 40 & 60 & 80 \\
\hline 60 & & $11,24 \pm 0,74^{\mathrm{aB}}$ & $10,67 \pm 0,35^{\mathrm{aB}}$ & $13,80 \pm 2,01^{\mathrm{aA}}$ \\
120 & $9,59 \pm 0,42^{\mathrm{bA}}$ & $7,68 \pm 0,69^{\mathrm{bB}}$ & $7,92 \pm 0,33^{\mathrm{bB}}$ \\
180 & & $8,96 \pm 0,65^{\mathrm{bA}}$ & $8,41 \pm 0,43^{\mathrm{bA}}$ & $8,20 \pm 0,66^{\mathrm{bA}}$
\end{tabular}

Letras minúsculas diferentes na mesma coluna indicam diferença estatística significativa $(p<0,05)$. Letras maiúsculas diferentes na mesma linha indicam diferença estatística significativa $(p<0,05)$.

\section{CONCLUSÃO}

A desidratação osmótica é uma boa alternativa para aumentar o período de conservação de morangos após sua colheita, por possibilitar a transformação do fruto, em um produto com maior valor agregado, aumentando a qualidade.

Recomenda-se que a desidratação osmótica de morangos seja realizada por meio da imersão dos frutos, durante 60 minutos, em solução de sacarose $80 \%$, o que proporciona maior perda de água, resultando assim em maior perda de massa, obtendo-se um produto de maior vida útil, menos suscetível a deteriorações.

\section{REFERÊNCIAS}

ANDRADE, S. A. C; NETO, B.B; NÓBREGA, A.C; AZOUBEL, P.M; GUERRA, N.B. Evaluation of water and sucrose diffusion coefficients during osmotic dehydration of jenipapo (Genipa Americana L.). Journal of Food Engineering, v. 78, n. 2, p. 551-555, 2007.

ANTUNES, L. E. C. Amora-preta: nova opção de cultivo no Brasil. Ciência Rural, v. 32, n. 1, p.151-158, 2002.

ASSOCIATION OF OFFICIAL ANALYTICAL CHEMISTS. Official Methods of Analysis of the Association of Official Analytical Chemists. Arlington: A.O.A.C.,1995.

CAMPOS, R.; RODOVALHO, M.A. Coating on 'Camarosa' organic strawberries stored at low temperature. Brazilian Journal of Food Technology., v. 12, n. 1, p. 60-67, 2009.

CIA, P.; BRON, I.U.; VAlENTINI, S. R. T.; PIO, R.; CHAGAS, E. A. Atmosfera modificada e refrigeração para conservação pós-colheita da amora-preta. Biosci. J., Uberlândia, v. 23, n. 3, p. 11-16, 2007. 
DEL-VALLE, V.; MUÑOZ, P.H; GUARDA, A.; GALOTTO, M.J.Development of a cactusmucilage edible coating (Opuntia ficus indica) and its application to extend strawberry(Fragaria ananassa) shelf-life. Food Chemistry, v.91, n.4, p. 751-756, 2005.

FERNANDES, F.A.N; RODRIGUES, S; GASPARETO, O.C.P; OLIVEIRA, E.L. Optimization of osmotic dehydration of bananas followed by air-drying. Journal of Food Engineering, v. 77, n. 1, p. 188-193, 2006.

GONÇALVES, E. D.; MALGARIM, M.B.; TREVISAN, R.; ANTUNES, L.E.C.; CANTILLANO, R.F.F. Conservação Pós-colheita de Amora-preta (Rubus sp). $1^{\circ}$ Seminário Brasileiro sobre Pequenas Frutas, Pelotas, p.226-230, 2004.

HAFFNER, K.; ROSENFELD, H.J.; SKREDE, G.; WANG, L. Quality of red raspberry Rubus idaeus L. cultivars after storage in controlled and normal atmospheres. Postharvest Biology and Technology, v.24, p.279-289, 2002.

HAN, C.; LEDERER, C.; MCDANIEL, M.; ZHAO, Y. Sensory Evaluation of Fresh Strawberries (Fragaria ananassa) Coated with Chitosan-based Edible Coatings. Journal of Food Science. v. 70,n.3, 2005.

KHOYI, M.R., HESARI, J. Osmotic dehydration kinetics of apricot using sucrose solution. Journal of Food Engineering, n.30, p.1-6, 2006.

KOWALSKA, H., LENART, A. Mass exchange during osmotic pretreatment of vegetables. Journal of Food Engineering, n.49, p.137-140, 2001.

MADAIL, J.C. M.; ANTUNES, L.E.; BELARMINO, L.C.; SILVA, B.A.; GARDIN, J. A. Avaliação Econômica dos Sistemas de Produção de Morango: Convencional, Integrado e Orgânico. Pelotas: Embrapa Clima Temperado, 4p. (Comunicado Técnico,181), 2007.

MIZKAHI, S., EICHLER, S., \& RAMON, O. Osmotic dehydration phenomena in gel systems. Journal of Food Engineering, v. 49, p. 87-96, 2001.

OLIVEIRA ,R.P; NINO, A.F.P; SCIVITTARO,W.B. Mudas certificadas de morangueiro: maior produção e melhor qualidade da fruta. A Lavoura 108: 35-38, 2005.

PARK, K. J.; BIN, A.; BROD, F. P. R. Drying of pear d'Anjou with and without osmotic dehydration. Journal of Food Engineering, v. 56, p. 97, 2002

SEBRAE. Disponível em: http://www.cbcde.org.br/pt/noticia/noticia.php. Acesso em: $20 / 12 / 2011$

TELES, U.M; FERNANDES, F.A.N; RODRIGUES, S; LIMA, A.S; MAIA, G.A; FIGUEIREDO, R.W. Optimization of osmotic dehydration of melons followed by airdrying. International Journal of Food Science and Technology, v. 41, n. 6, p. 674-680, 2006. 
TELIS, V. R. N., MURARI, R. C. B. D. L., \& YAMASHITA, F. Diffusion coefficients during osmotic dehydration of tomatoes in ternary solutions. Journal of Food Engineering, v. 61,p. 253-259, 2004.

TORREGGIANI, D. Osmotic dehydration in fruit and vegetable processing. Food Research International, v. 26, p.59-68, 1993.

VARGAS, M.; ALBORS, A.; CHIRALT, A.; GONZÁLEZ-MARTÍNEZ, C.Quality of coldstored strawberries as affected by chitosan-oliec acid edible coatings. Postharvest Biology and Technology,v.41, p.164-171, 2006.

VIBERG, U., FREULER, S., VASSILIS, G., SJÖHOLM. Osmotic Pretreatment of Strawberries and Shrinkage Effects. Journal of Food Engineering, n.35, p.135-145, 1998. 